6. Moberg, A., Bergström, H., Ruiz Krisman, J. \& Svanerud, O. Climatic Change 53, 171-212 (2002).

7. Sutton, R. T. \& Dong, B. Nature Geosci. 5, 288-292 (2012).

8. Statistics Sweden (accessed 28 October 2013); http://www.scb.se/

9. Oudin Åström, D., Forsberg, B., Edvinsson, S. \& Rocklöv, J. Epidemiology 24, 820-829 (2013).
10. Fouillet, A. et al. Int. J. Epidemiol. 37, 309-317 (2008).

11. Palecki, M. A., Changnon, S. A. \& Kunkel, K. E.

Bull. Am. Meteorol. Soc. 82, 1353-1367 (2001).

Paul Knappenberger ${ }^{1 \star}$, Patrick Michaels

and Anthony Watts ${ }^{2}$
${ }^{1}$ Cato Institute, 1000 Massachusetts

Ave, NW, Washington DC 20001, USA,

${ }^{2}$ IntelliWeather, 3008 Cohasset Rd Chico,

California 95973, USA

*e-mail: pknappenberger@cato.org

\title{
Reply to 'Adaptation to extreme heat in Stockholm County, Sweden'
}

Oudin Åström et al. reply — We thank Knappenberger and colleagues for their interest in our research ${ }^{1}$. Their correspondence expresses two concerns: a possible bias in the temperature data ${ }^{2}$ and appropriate consideration of adaptation to extreme-heat events over the century. To clarify, we estimated the impacts of observed climate change over the century on temperature-related mortality; our purpose was not to determine what caused the climatic changes. Our study aimed to examine the health impacts of temperature extremes on the population during the period 1980-2009, given the societal and infrastructure changes that occurred over the twentieth century, if this population had experienced the climate of the period 1900-1929. We did not adjust for actual adaptation responses because the low public awareness of the health hazards of high ambient temperature suggests that there would have been limited autonomous adaptation, and because data were not available to adjust for any actual adaptation responses. We did not compare the relative risk of mortality during an extreme day between 1900-1929 and 1980-2009, as this would be misleading.

With respect to the temperature data, we compared the station data recorded during the two study periods (1900-1929 versus 1980-2009). To limit the influence of regional and decadal variability, we used the standard approach of comparing patterns over 30-year time periods. The observed changes are the result of natural processes, including regional climate variability, and anthropogenic influences, including urbanization ${ }^{3}$.

Our method of comparing the climate during two 30-year periods is valid for any two periods. Sensitivity analyses using different reference periods when calculating the cut-off temperatures (1910-1939, 1920-1949, 1930-1959, 1940-1969 and 1950-1979) limit the influence of the Atlantic Multidecadal Oscillation (AMO) ${ }^{4}$. For all periods that were investigated, the increase in the number of excess heat extremes ranges from 77 for the reference period 1930-1959 to 158 for the reference period 1950-1979. The AMO during the 1990s was similar to the warm state of 1931-1960 during which there was an increase in the number of heat extremes, albeit not to the extent of the original reference period.

We appreciate the opportunity to correct any misperceptions about adaptation to heat extremes in Stockholm. Our data indicate that there is no adaptation to heat extremes on a decadal basis or to the number of heat extremes occurring each year. Although another study observed a reduction in the population health impact of hot and cold extremes over the twentieth century ${ }^{5}$, this decrease should not be confused with adaptation to climatic change. As in the studies cited by Knappenberger et al., socio-economic development, epidemiological transitions and health system changes were and continue to be the main drivers of changes in population sensitivity - not explicit, planned actions to prepare for climate change impacts. These changes also apparently increased population resilience to climate change. Whether future development pathways will continue to increase resilience will also depend on many factors other than climate change. Importantly, it is not appropriate to assume that historic trends will continue, with or without climate change.

References

1. Oudin Åström, D., Forsberg, B., Ebi, K. L. \& Rocklöv, J. Nature Clim. Change 3, 1050-1054 (2013).

2. Moberg, A., Bergström, H., Ruiz Krisman, J. \& Svanerud, O. Climatic Change 53, 171-212 (2002)

3. IPCC Climate Change 2013: The Physical Science Basis (eds Stocker, T. F. et al.) (Cambridge Univ. Press, 2013)

4. Sutton, R.T. \& Dong, B. Nature Geosci. 5, 788-792 (2012).

5. Oudin Åström, D., Forsberg, B., Edvinsson, S. \& Rocklöv, J. Epidemiology 24, 820-829 (2013).

Daniel Oudin Åström ${ }^{1 \star}$, Bertil Forsberg ${ }^{1}$, Kristie L. Ebi' and Joacim Rocklöv ${ }^{2}$

'Department of Public Health and Clinical Medicine, Division of Occupational and Environmental Medicine, Umeå University, 90187 Umeå, Sweden, ${ }^{2}$ Department of Public Health and Clinical Medicine, Division of Epidemiology and Global Health, Umeå University, 90187 Umeå, Sweden.

^e-mail: daniel.astrom@envmed.umu.se

\section{COMMENTARY:}

\section{Costing natural hazards}

\author{
Heidi Kreibich, Jeroen C. J. M. van den Bergh, Laurens M. Bouwer, Philip Bubeck, Paolo Ciavola, Colin Green, \\ Stephane Hallegatte, Ivana Logar, Volker Meyer, Reimund Schwarze and Annegret H. Thieken
}

\section{The proposed 'cost assessment cycle' is a framework for the integrated cost assessment of natural hazards.}

eported costs of natural hazards are at historically high levels, and are rising due to the ever increasing cost of events with large-scale effects.

The Thailand flood in 2011, for example, shut down scores of factories, damaging global car manufacturing and electronics industries. In 2013, Typhoon Haiyan in the Philippines caused many casualties and displaced thousands of people. Globally in 2013, natural hazards caused damage estimated at US\$125 billion ${ }^{1}$. Property damage has doubled about every seven years over the past four decades ${ }^{2}$.

But such assessments generally do not reflect the complete set of costs of natural hazards, which comprise direct, business interruption, indirect, intangible and risk 